\title{
COMPREENDENDO AS DECISÕES JUDICIAIS A PARTIR DE MODELOS
}

MATEMÁTICOS I UNDERSTANDING JUDICIAL DECISIONS FROM

MATHEMATICAL MODELS

ANA KEULY LUZ BEZERRA JOSÉ MACHADO MOITA NETO

RESUMO I A matemática tem modelado bem os sistemas físicos apenas por não apresentar modelos únicos dos fenômenos. Aqui descrevemos quatro tipos de modelos matemáticos com grande impacto na descrição do mundo físico. Enquanto nas ciências duras estes modelos são simples instrumentos para explicar o mundo físico, quando aplicados para a realidade social perdem seus contornos precisos e transformamse em modos de compreensão da realidade. O objetivo deste estudo é construir uma tipologia de problemas jurídicos a partir destes modelos matemáticos de maior destaque. A análise foi feita a partir de julgados extraídos de tribunais diversos a fim de correlacioná-los com as teorias suscitadas neste ensaio. Em síntese, descreve-se alguns aspectos do mundo jurídico por comparação com modelos matemáticos existentes. Por óbvio não se esgota a complexidade do direito pela redução a quatro modos de enxergá-lo.

PALAVRAS-CHAVE | Modelos matemáticos. Decisões judiciais. Atratores. Problemas jurídicos. Realidade Social.

\begin{abstract}
Mathematics has well modeled physical systems because it does not provide unique models of phenomena. In this article, we described four types of mathematical models with great impact on the description of the physical world. While in the hard sciences these models are simple tools to explain the physical world, when applied to social reality, they lose their precise contours and become modes of understanding reality. The aim of this study is to construct a typology for legal problems from these most significant mathematical models. The analysis was carried out from judicial decisions made various courts in order to correlate them with the theories mentioned in this essay. To sum up, we described some aspects of the legal world by comparing them with existing mathematical models. Obviously, the complexity of law does not exhaust after reducing it to four modes of analysis.
\end{abstract}

KEYWORDS | Mathematical models. Judicial decisions. Attractors. Legal issues. Social Reality. 


\section{INTRODUÇÃO}

s irregularidades ao longo da história da jurisprudência
brasileira nos levam a tentar compreendê-las sob vários
olhares disciplinares. Sendo inclusive possível utilizar as consequências quantitativas dos modelos matemáticos, posto que, em algumas vezes, as sentenças são totalmente previsíveis, em outros dentro de uma lista de possibilidades, já conhecida pelos que aguardam a decisão, e finalmente há os casos, nos quais os desfechos são totalmente surpreendentes. "A ciência mostra que a imprevisibilidade não é resultado da ignorância do homem em não saber resolver uma equação, mas da forma como o mundo existe" (MARTINS, 2011, p.3).

O presente estudo tem como objetivo verificar a aplicação da modelagem matemática qualitativa no direito, e analisar se através desta é possível definir o nível de previsibilidade e aplicabilidade das decisões judiciais. A análise foi feita a partir de casos julgados e/ou situações, nos quais foi possível associá-los com as teorias determinística, probabilística, da fractalidade e do caos, suscitadas na pesquisa.

O próprio surgimento da norma jurídica denota de relações lógicomatemáticas entre o homem e a sociedade, através das quais confirma-se a necessidade da regulamentação para uma convivência harmônica.

Numa sociedade, certas exigências serão sempre permitidas, e certas proibições, sempre impostas. Isto decorre da função instrumental das sociedades humanas. Os movimentos que podem ser oficialmente exigidos e oficialmente proibidos são consignados em mandamentos, em imperativos, que compõem o ordenamento jurídico.

O direito objetivo (o conjunto de todas as normas jurídicas ou normas de direito) de uma sociedade nem sempre coincide com o direito objetivo que os componentes dessa sociedade gostariam de ver vigorante. $\mathrm{O}$ direito objetivo desejado pelos componentes da sociedade é sempre aquele que melhor possa 
fazer, da sociedade, o ambiente em que todos usufruam de seus bens soberanos $^{1}$ (TELLES JÚNIOR, 2006).

Por tais motivos, pode-se dizer que a história do ser humano é causa e efeito dele próprio. É efeito de determinações da inteligência. E é causa das formas culturais, que, em cada circunstância, determinam cada homem. Bem pouco, ou nada, se conhecerá do ser humano, se não tiver se alcançado esta verdade.

As coisas do mundo, inclusive os fatos sociais, não são consideradas, pelo ser humano, como simples dados, como objetos apenas ocupando espaço e tempo, dentro do universo. Não são consideradas como coisas meramente relacionadas umas com as outras por nexos físicos de causalidade. Elas têm um sentido, um sentido para o ser humano.

É o que está confirmado pela variação dos critérios de julgamento em povos e tempos diferentes. A experiência jurídica é sempre a atualização objetiva de um estado de consciência de uma comunidade. É a objetivação do que é considerado jurídico dentro de um grupo social. Em outras palavras, é a vivência daquilo que uma comunidade, por convicção generalizada, qualifica de jurídico num determinado momento histórico e num determinado lugar.

A experiência jurídica atinge o simples e o complexo, tal como os fenômenos físicos, estes, porém apoiados em modelos matemáticos para melhor compreender o mundo físico.

Nesse sentido, questiona-se: podem as teorias matemáticas nos ajudar a moldar a experiência jurídica e instigar uma atualização dos valores da sociedade? Pensando assim, é possível identificar modelos matemáticos na interpretação e construção de um direito jurisprudencial? Estas são as questões centrais deste estudo.

1 Os bens soberanos tem existência histórica e mudam de acordo com as circunstâncias. Os sistemas éticos de referência das sociedades humanas se transformam e, com elas, as fisionomias das civilizações e seus bens considerados soberanos. (TELLES JÚNIOR, 2006, p.349). 


\section{MATERIAL E MÉTODOS}

O método consistiu em apresentar aspectos de quatro modelagens matemáticas: o determinismo, a probabilidade, a fractalidade e o caos, usando como gancho o fio da relacionalidade destas com a ciência jurídica. Trata-se de um experimento que sugere conexões com casos jurídicos concretos e que resultou na interpretação lógica pretendida.

Este exercício compreendeu dois passos. Primeiro, uma discussão sucinta dos conceitos matemáticos de cada teoria encontrados na literatura da área. Segundo, apresenta-se os casos concretos nos quais se sugere a aplicação das relações matemáticas conceituadas.

Os processos selecionados que serviram de parâmetro para exemplificação das teorias matemáticas no presente estudo tiveram seus temas definidos a partir da práxis dos autores no exercício da advocacia, e os critérios de busca utilizados para cada teoria foram:

a) Teoria Determinística: o tema escolhido foi "a nomeação e posse de candidatos com qualificação superior à exigida no Edital do certame público" e os critérios de busca foram: Competência da Justiça Federal; um julgamento do tema definido oriundo de cada região do Tribunal Regional Federal, totalizando cinco processos, escolhidos de forma aleatória dentre a lista de resultados obtidos no sistema de consulta processual de cada TRF.

b) Teoria Probabilística: o tema escolhido foi "possibilidade ou não de participação de alunos em solenidade de colação de grau de forma simbólica" e os critérios de busca foram: competência: Justiça Federal; Jurisdição: Seção Judiciária do Piauí; Órgãos julgadores: Varas cíveis $\left(1^{\mathrm{a}}, 2^{\mathrm{a}}, 3^{\mathrm{a}}\right.$ e $\left.5^{\mathrm{a}}\right)$. A partir dos critérios foi feita busca no sistema de consulta processual do TRF 1 - SJPI, o que resultou em 20 processos, nos quais foram verificados os resultados das decisões liminares para se observar a repetição dos resultados, em seguida foi escolhido de forma aleatória um processo de cada Vara para utilizar no presente estudo como referência. 
c) Teoria da Fractalidade: o tema escolhido foi a "validade da aplicação da Taxa Referencial - TR como índice de correção monetária dos depósitos efetuados na conta vinculada ao Fundo de Garantia por Tempo de Serviço FGTS" e a busca foi feita no site do Superior Tribunal de Justiça (STJ), observando os seguintes critérios: processos repetitivos; assunto: correção do FGTS, o que resultou em 49 processos, dentre os quais foi escolhido, de forma aleatória, o Resp 1.381.683 - PE para utilização no presente estudo.

d) Teoria do Caos: o ramo do direito ambiental foi pensado a partir de estudos anteriores dos pesquisadores, nos quais foi observada a complexidade dos casos levados ao judiciário frente à dificuldade dos magistrados para decidir nestes processos. Definido o ramo do direito, foi feita pesquisa sobre as demandas ambientais recorrentes nos Tribunais Brasileiros (no site jusbrasil.com.br), que resultou na "instalação de usinas hidrelétricas", e devido à grande repercussão e notoriedade, foi selecionado de forma intencional o caso da Usina de Belo Monte no estado do Pará para o presente estudo.

\section{DETERMINISMO JURÍDICO}

A concepção determinista pressupõe que os acontecimentos do mundo são preestabelecidos, previsíveis. Ao passo que, a concepção indeterminista argumenta que existem acontecimentos que não são previsíveis. Mesmo com concepções distintas, os defensores do determinismo admitem que mesmo que o futuro esteja determinado, pode nos ser incerto (POPPER, 1988).

A confiança extrema de Laplace na matemática levou-o ao extremo de imaginar uma previsibilidade absoluta por meio de fórmulas, que rivaliza-se com o atributo divino da onisciência, dizendo:

Devemos considerar o estado presente do universo como consequência do seu estado anterior e como a causa do estado seguinte. Uma inteligência que, num determinado momento, conhecesse todas as forças que animam a natureza e a respectiva situação dos seres que a compõem se, além disso, ela fosse suficientemente poderosa para analisar estes dados e juntasse em uma mesma fórmula os movimentos dos maiores corpos do universo e os dos menores átomos: nada seria incerto para ela, e o futuro, assim como o passado, estaria presente aos seus olhos (LAPLACE, 1990, p. 326). 
Laplace (1990) declara que a Natureza é determinista, mas que ela se comporta como um relógio de tamanho e complexidade gigantescas. É exatamente essa complexidade que pode tornar conveniente, mas não necessário, tratar certas decisões do judiciário como deterministas. De tal modo que, ao propor o objeto da ação, já exista a certeza do resultado que será produzido pelo julgador, o exercício de previsibilidade aqui é fácil, e a aleatoriedade é praticamente descartada.

Salutar destacar que o determinismo, como pressuposto científico, não ficou restrito apenas às ciências exatas; abrangia todas as ciências naturais até a segunda metade do século XIX, e as ciências humanas e sociais também sofreram a influência desta concepção. A figura 1 contempla o que é proposto fazer com o direito:

Figura 1: Relação determinística no direito
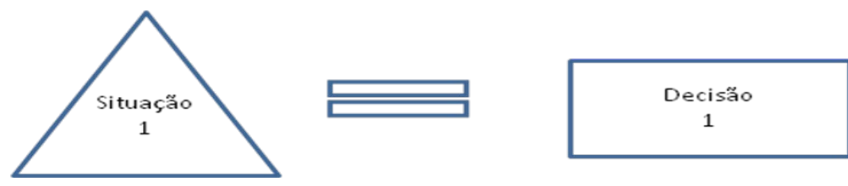

Fonte: Autores, 2020.

No direito, o que é pensando como determinismo são aquelas situações que são levadas ao judiciário para as quais existe a certeza do resultado. Para todas as ações impetradas com aquele objeto, o resultado será sempre o mesmo, não há nenhum grau de incerteza sobre o resultado do processo. Pois é sabido que aquela situação 1 sempre terá como resultado a decisão 1.

Para exemplificar, cita-se os 5 julgados selecionados de cada região dos Tribunais Regionais Federais:

APELAÇÃo CíVEL. REEXAME NECESSÁRIO. MANDADO DE SEGURANÇA. CONCURSO PÚBLICO. CARGO DE TÉCNICO DE LABORATÓRIO/ÁREA QUÍMICA. EXIGÊNCIA DE FORMAÇÃO EM NÍVEL MÉDIO. COMPROVAÇÃO DE CONCLUSÃO DE CURSO SUPERIOR DE QUÍMICA. REQUISITOS SATISFEITOS. SENTENÇA MANTIDA. (REOMS 0000224-22.2010.4.01.4300 / TO, Rel. DESEMBARGADOR FEDERAL JIRAIR ARAM MEGUERIAN, SEXTA 
TURMA, e-DJF1 p.111 de 25/03/2013). 4. Apelação e Remessa oficial a que se nega provimento. (TRF-1 - AMS: 31062520134013823, Relator: DESEMBARGADOR FEDERAL KASSIO NUNES MARQUES, Data de Julgamento: 16/06/2014, SEXTA TURMA, Data de Publicação: 22/07/2014).

ADMINISTRATIVO - APELAÇÃO EM MANDADO DE SEGURANÇA - CONCURSO PÚBLICO PARA O CARGO DE TÉCNICO EM NUTRIÇÃO - CANDIDATO COM QUALIFICAÇÃO SUPERIOR À EXIGIDA NO EDITAL (BACHAREL EM NUTRIÇÃO) - DESCUMPRIMENTO DO EDITAL - INOCORRÊNCIA. (TRF-2 REEX: 201150010017889, Relator: Desembargadora Federal CARMEN SILVIA LIMA DE ARRUDA, Data de Julgamento: 19/03/2012, SEXTA TURMA ESPECIALIZADA, Data de Publicação: 27/03/2012)

ADMINISTRATIVO. CONCURSO PÚBLICO. NOMEAÇÃO E POSSE. CANDIDATO COM QUALIFICAÇÃO SUPERIOR À EXIGIDA NO EDITAL. (TRF-3 - Apelação/Reexame Necessário 0002166-31.2014.4.03.6002/MS).

ADMINISTRATIVO. CONCURSO PÚBLICO. NOMEAÇÃO E POSSE. CANDIDATO COM QUALIFICAÇÃO SUPERIOR À EXIGIDA NO EDITAL. (TRF-4 - APELREEX: 50597118220134047100 RS 5059711-82.2013.404.7100, Relator: MARGA INGE BARTH TESSLER, Data de Julgamento: 26/03/2014, TERCEIRA TURMA, Data de Publicação: D.E. 27/03/2014).

CONSTITUCIONAL. ADMINISTRATIVO. CANDIDATO APROVADO. QUALIFICAÇÃO SUPERIOR À EXIGIDA NO EDITAL. PRINCÍPIO DA RAZOABILIDADE E DA ACESSIBILIDADE AOS CARGOS PÚBLICOS. (TRF-5 - REEX: 2315720124058107, Relator: Desembargador Federal Ivan Lira de Carvalho, Data de Julgamento: 08/04/2014, Quarta Turma, Data de Publicação: 11/04/2014).

Nestes casos, o que ocorre é que o autor da ação é aprovado em um concurso público para um cargo técnico, para o qual é exigida a qualificação de nível médio, mas este possui a qualificação exigida em nível superior (cursos de graduação). Neste caso, quando o candidato é nomeado para o cargo, e apresenta-se ao órgão contratante, este o recusa, alegando que o candidato não apresenta a qualificação exigida pelo edital regulamentador. O candidato, sentindo-se lesado busca amparo no judiciário para ver sua pretensão à ocupação do cargo público ser concretizada.

As decisões em todo o Brasil, a exemplo dos julgados apresentados, para casos semelhantes a este, têm sido no sentido de conceder a liminar e depois em sede de mérito confirmar a liminar, para que estes candidatos tomem posse nos respectivos cargos. Apesar de não haver nenhum instituto formal que obrigue os julgadores a manter esse posicionamento. 
O judiciário ao apreciar essas ações decide que, apesar de o edital regulador do concurso estipular que para o cargo perquirido o candidato deve possuir "Ensino médio profissionalizante na área ou ensino médio completo + Curso Técnico" na área, se o candidato apresenta qualificação por meio de diploma de curso superior, deve tomar posse no cargo de Técnico para o qual obteve informação.

Predomina o entendimento que em verdade a norma editalícia fixou tão somente preceito mínimo a ser exigido do candidato no ato do provimento. Nesse contexto, a comprovação de capacidade profissional superior à exigida não pode, de maneira alguma, prejudicar o interessado sob pena de macular, irremediavelmente, a razoabilidade administrativa, a eficiência e a qualidade do serviço a ser prestado.

Por fim, salutar destacar o posicionamento do TRF da $1^{\text {a }}$ Região, no qual o Piauí está inserido, que já sedimentou que:

\footnotetext{
Assente nesta Corte o entendimento no sentido de que a comprovação de que o candidato a cargo público possui grau de escolaridade superior ao exigido pelo edital do certame lhe confere direito líquido e certo à nomeação e posse, não se mostrando razoável impedir seu acesso ao serviço público. (REOMS 0000224-22.2010.4.01.4300 /TO, Rel. DESEMBARGADOR FEDERAL JIRAIR ARAM MEGUERIAN, SEXTA TURMA, e-DJF1 p.111 de 25/03/2013).
}

A situação exposta, apesar do entendimento pacificado demonstrado, não inibe novas recusas pelas instituições contratantes, que defendem-se sob a alegação de observância ao princípio da legalidade, ou seja, o estrito cumprimento das regras editalícias, e de que a Carreira do Pessoal TécnicoAdministrativo apresenta, dente outras exigências, aquelas pertinentes à observância dos requisitos para investidura nos cargos respectivos, que não são contempladas pela formação em curso superior.

Em que pesem os argumentos dos órgãos recorridos, os mesmos não têm convencido o judiciário a modificar o entendimento sedimentado até $\mathrm{o}$ momento, podendo assim, o raciocínio determinístico aqui apresentado aplicar- 
se perfeitamente aos casos em tela, posto que as dúvidas sobre o deslinde processual destes feitos não existem.

\section{PROBABILIDADES: DIVERGÊNCIA DOUTRINÁRIA E PLASTICIDADE LEGISLATIVA}

Por muitos milhares de anos que o povo passou apostando em jogos de azar, eles não tinham uma maneira de calcular as probabilidades de diferentes resultados além daqueles poucos que são muito óbvios ou para os quais é fácil enumerar as possibilidades.

A probabilidade - a chance ou possibilidade de um evento acontecer entrou para a matemática no século XVII no contexto dos jogos de azar. Embora os jogos de azar continuassem a interessar os matemáticos, outro ímpeto era a ideia legal de um contrato justo. Em um contrato justo, as partes têm expectativas iguais. Era um conceito importante porque as expectativas justas estavam na essência da justificação do empréstimo de dinheiro. Até o século XVII, as taxas para empréstimos e rendas anuais eram fixadas sem nenhuma consideração por qualquer conceito matemático de risco, ou como estas poderiam ser calculadas (ROONEY, 2012).

A probabilidade não consolidou-se como um conceito matemático exato até o século XVIII, sendo ainda geralmente considerada uma ideia indistinta no bom senso do século XIX. Laplace, por exemplo, referia-se à probabilidade como "bom senso reduzido ao cálculo".

Em 1657-58, Blaise Pascal escreveu um ensaio filosófico no qual descrevia a "aposta" que um cético poderia fazer. O castigo por não acreditar em Deus poderia ser a desgraça eterna; no entanto, o custo de acreditar em Deus se por acaso ocorresse de Ele não existir seria mínimo (ROONEY, 2012).

Uma situação mais difícil para os matemáticos modelarem é aquela em que as ações de uma pessoa são dependentes ou vinculadas com aquelas de outra pessoa, como acontece no direito. Isto é estudado pela teoria dos jogos, 
desenvolvida na década de 1940 pelo matemático húngaro-americano John Von Neumann e pelo alemão-americano Oskar Morgenstern (BOYER, 1996).

Quando as pessoas fazem escolhas, elas tentam maximizar os benefícios para si próprias. Elas podem também tentar minimizar o prejuízo para os outros - ou podem não dar nenhuma atenção ao impacto sobre os outros, até mesmo agir no sentido de prejudicá-los.

A Teoria dos jogos, segundo Nash, traz dois resultados distintos. Para interações imediatas, a postura de competição ou traição é a mais favorável. Neste caso podemos citar como exemplo jurídico a delação premiada - que tem sido inclusive estimulada pelos operadores do direito em nosso país -, na qual ganha mais quem trai primeiro. Já para interações de longa duração, o melhor ganho ocorre em posturas colaborativas ou harmônicas. No longo prazo o modelo é a mediação familiar, a cooperação entre os pais na guarda compartilhada é essencial para desenvolvimento da criança, também esta opção foi contemplada em nosso ordenamento jurídico nos termos da Lei $13.058 / 2014$.

A teoria dos jogos tenta levar em conta os motivos das pessoas que estão agindo na situação que é modelada, bem como muitos outros aspectos relevantes. A teoria dos jogos muitas vezes produz uma matriz de resultados que podem então ser analisados. Por analogia, em alguns casos jurídicos, os advogados, ao proporem determinada ação, já estão cientes da matriz de resultados possíveis para seu processo. Isso feito, a partir dos entendimentos jurisprudenciais anteriores ao seu, resta-Ihe apenas aguardar a confirmação de uma daquelas possibilidades.

No entanto, para que a probabilidade pudesse ser usada eficazmente em qualquer área, eram necessárias informações confiáveis. Nesse sentido, a estatística e a probabilidade andam de mãos dadas. Sem informações sobre as quais basear as decisões, é possível calcular somente probabilidades mais básicas. 
Quando pensamos a probabilidade no mundo jurídico, nos perguntamos se estatisticamente seria possível a previsão de um resultado sobre o deslinde de um processo no ato de sua distribuição.

De alguma forma o resultado poderia ser conhecido previamente, bastando que houvesse um conhecimento pregresso acerca dos posicionamentos dos julgadores sobre determinada matéria jurídica. A figura 2 demonstra a teoria probabilística jurídica:

Figura 2: Relação probabilística no direito

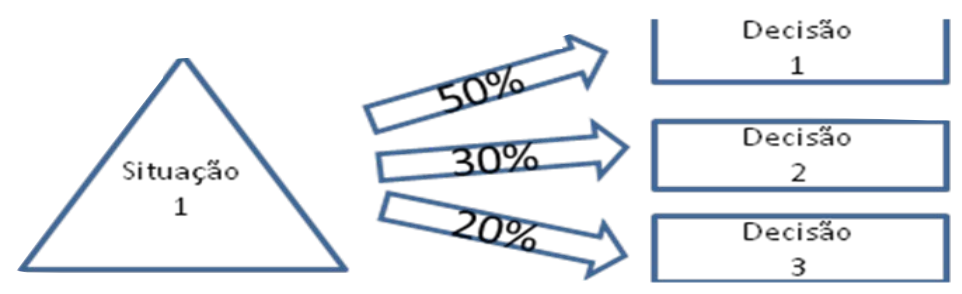

Fonte: Autores, 2020.

$\mathrm{Na}$ figura 2, para cada situação 1 apresentada ao judiciário, existem três possibilidades de resultado: a decisão 1 , a decisão 2 , ou a decisão 3 . Diferente do que ocorre no determinismo, aqui não há exatidão quanto ao resultado do julgamento, mas é possível definir um conjunto de possibilidades com os possíveis resultados, dentre as quais, aquela que será aplicada ao caso em apreço.

Para exemplificar a aplicação da probabilidade no direito, nos valemos de quatro processos oriundos da Seção Judiciária do Piauí, com o tema: possibilidade ou não da participação de alunos em solenidade de colação de grau, de forma simbólica, ante a pendências acadêmicas.

Nessas ações, os autores alegam principalmente, os dispêndios financeiros já realizados ao longo do curso para o custeio da cerimônia, e que a pendência (uma ou duas disciplinas) é mínima quando comparada à carga horária já concluída do curso. E ainda alegam a necessidade de comemorarem esse momento junto com seus colegas de turma e sua família de forma festiva, e não em uma simples cerimônia de gabinete, como teria que ser nesses casos. 
Ao se verificar as decisões liminares desse tipo de ação, obteve-se o seguinte resultado: a $1^{\text {a }}$ Vara sempre indefere o pedido, independentemente da situação do aluno demandante, e a $2^{\mathrm{a}}, 3^{\mathrm{a}}$ e $5^{\mathrm{a}}$ Vara sempre deferem o pedido, também independentemente da pendência do aluno demandante.

\begin{abstract}
Processo 1: $n^{0}$. 0005070-70.2014.4.01.4000 - $1^{\text {a }}$ Vara Federal - Resultado: Indeferido. Com efeito, em que pese a existência de precedentes favoráveis à pretensão do pleiteante, este Juízo considera que a colação de grau, enquanto cerimônia pública, coletiva, tem uma feição solene essencial, consubstanciando $\mathrm{o}$ ato pelo qual a entidade não somente confere aos formandos o grau respectivo, mas igualmente apresenta à sociedade os seus novos bacharéis, licenciados etc. Nestas condições, ao ver deste Magistrado, a participação na solenidade de alguém que não detém as condições para a obtenção do grau (ainda que de modo meramente simbólico) implicará para a grande maioria dos presentes - que não têm conhecimento da situação - uma farsa, um embuste, determinado pelo Poder Judiciário. Diante disso, considerando que o discente não atende aos requisitos que lhe assegurariam a participação no ato, já que se encontra pendente em uma disciplina, não se faz presente qualquer ilegalidade e/ou abuso de poder por parte do Diretor da Instituição, que possam ensejar a intervenção do Judiciário. Portanto, por não vislumbrar qualquer ilegalidade ou abuso de poder, impõe-se indeferir o pedido de liminar.
\end{abstract}

Processo 2: $\mathrm{n}^{\mathrm{o}}$. 0019896-38.2013.4.01.4000 - $2^{\mathrm{a}}$ Vara Federal - Resultado: Deferido. Ante o exposto, defiro o pedido liminar para determinar que o impetrante participe de forma "simbólica" de solenidade de colação de grau do curso de Administração ministrado pelo Instituto Camilo Filho, juntamente com os demais formandos da turma, com as devidas honras de mérito e recebimento formal do diploma, a se realizar em 30/08/2013, desde que o único óbice a pendências das disciplinas aqui relatadas.

Processo 3: $n^{0}$. 0005217-96.2014.4.01.4000 - $3^{\text {a }}$ Vara Federal - Resultado: Deferido. Pelo exposto, DEFIRO o pedido de liminar para determinar à Universidade Impetrada permita a participação da Impetrante, de forma simbólica, na cerimônia de colação de grau juntamente com os demais formandos do curso de Administração do Instituto Camilo Filho, prevista para o dia 20/03/2014, garantindo-lhe, outrossim, a chamamento oficial, entrada com seus padrinhos e recebimento de canudo simbólico.

Processo 4: $n^{0}$. 0019888-61.2013.4.01.4000 - 5 ${ }^{\text {a }}$ Vara Federal - Resultado: Deferido. Pelo exposto, defiro o pedido de liminar somente para determinar à autoridade coatora que realize, de forma simbólica, a colação de grau da impetrante juntamente com os demais formandos do curso de Administração da Faculdade Camilo Filho - 2013.1, desde que o único óbice seja a não conclusão da disciplina Ética Empresarial.

\footnotetext{
Deduz-se assim que um postulante desta Seção Judiciária que pretende obter uma decisão liminar para colação de grau simbólica em curso superior em razão de pendências exclusivamente acadêmicas, com os critérios
} 
jurisdicionais já citados, tem $75 \%$ (setenta e cinco por cento) de probabilidade de obter êxito em seu pleito.

Isso porque, só não conseguirá a liminar para a finalidade de colação de grau simbólica, aquele que tiver seu processo distribuído para a $1^{\text {a }}$ Vara. Vale destacar que todas as decisões destacadas são fundamentadas em dispositivos legais e no próprio entendimento do hermeneuta, utilizando-se nesse caso do princípio do livre convencimento motivado, que the é assegurado, o que, na maioria das vezes, provoca a variação ou não, dos resultados dos julgados.

Quem pode valer-se positivamente, tanto da teoria determinística, como da probabilidade aplicada aos resultados de demandas judiciais, são os advogados. Desde que estejam atentos para a repetição e a forma como estes julgamentos ocorrem. De posse dos dados estatísticos, podem informar melhor seu cliente quanto às chances reais de êxito em determinadas ações, e ao mesmo tempo, deixar o cliente ciente das possibilidades de fracasso no pleito, por menores que sejam.

Mesmo não sendo o direito uma atividade "fim", mas de "meio" - ou seja, não se trabalha por um resultado específico no processo - as interpretações matemáticas servem como parâmetro, e até mesmo como instrumento "motivador" para atuar no caso, pois pode dispor de um leque de possibilidades, para os quais vai preparar as respectivas argumentações no caso das probabilidades, ou mesmo no determinismo, objetivando apresentar ao magistrado novos argumentos para convencê-lo a mudar seu posicionamento.

\section{FRACTALIDADE: PRINCÍPIOS COMUNS NA CONSTRUÇÃO DO DIREITO}

Benoit Mandelbrot (MANDELBROT, 1983), o criador dos Fractais, insiste e mostra que é a geometria fractal, e não a geometria clássica euclidiana, a que realmente reflete a geometria dos objetos e dos processos do mundo real (SECCO; ROCHA, 2004). 
A palavra Fractal vem do Latim "fractus", que quer dizer fragmentado, fracionado. E mais: "Frac" dá a ideia de fração (parte), e "tal" dá a ideia de total (todo). Fractal significa auto-semelhante. Auto-semelhante é a simetria das escalas, significa recorrência, um padrão dentro de outro padrão. Daí a ideia de que a parte está no todo e o todo está na parte (GLEICK, 1990).

De acordo com Secco; Rocha (2004, p.1), as imagens dos fractais "se assemelharam a elas mesmas quando observadas de diferentes escalas de tamanho". Fractais têm sido usados para descrever muitos aspectos da natureza. Biólogos utilizam fractais para investigar a influência da superfície irregular de proteínas nas interações moleculares, matemáticos montam modelos de crescimento demográficos, modeladores gráficos os utilizam para a geração de terrenos e atmosferas, e também na arte produzida por computadores, temos encontrado figuras fractais.

A alteração promovida no Código de Processo Civil de 1973 por meio da Lei $n^{\circ} 11.672 / 2008$ e preservada no Novo CPC Lei 13.105/2015 no art. 1.036 trouxe nova sistemática de processamento dos recursos excepcionais, instituindo mecanismos de julgamento uniformes de recursos "repetitivos" (rectius: fundados em idêntica questão de direito) no âmbito dos Tribunais Superiores, que baseia-se na similaridade da parte com o todo, ou seja, na auto-semelhança dos casos concretos.

A técnica que o legislador indica para analisar os recursos "repetitivos" amolda-se ao conceito matemático de fractalidade, pois, ao apreciar um caso, selecionado a partir de um universo, aplica-se o resultado da decisão a todos os outros que a este se assemelham. Neste sentido, o caso selecionado representa todas as ações fundadas no mesmo objeto, e o todo estará representando no único caso concreto selecionado como paradigma.

A sistemática em apreço está contemplada no art. 1.036 do Novo CPC. Conforme referido dispositivo, quando o Presidente ou Vice-Presidente do Tribunal de origem detectar a existência de vários recursos que versam sobre uma mesma questão de direito, cumprir-lhe-á selecionar dois ou mais recursos representativos (fractais) para apreciarem e aplicar o seu resultado aos demais que versem sobre a mesma matéria. 
A seleção do paradigma deverá ser criteriosa, dando-se preferência àqueles recursos que contenham maior diversidade e clareza de argumentos para que se viabilize a análise mais detalhada possível por parte do Tribunal ad quem (art. $1^{\circ}, \S 1^{\circ}$, da Resolução $n^{\circ} 8 / 2008$ do STJ).

Uma vez selecionado, o recurso "paradigma" deixa de ser visto apenas sob o ângulo do suposto direito de determinada pessoa ("a parte") e passa a representar um instrumento processual de uniformização de uma questão de direito cuja pacificação interessa direta ou indiretamente a todo um plexo de pessoas ("o todo"), agora coletivamente consideradas. Eis ai contemplado o conceito de fractalidade (SILVA, 2011).

Por outro lado, os que não forem selecionados como "representativos" (no nosso caso, o todo) serão sobrestados após a devida certificação nos autos (art. $1^{\circ}, \S^{\circ}$, da Resolução $n^{\circ}$ 8/2008) e aguardarão em cartório o pronunciamento definitivo do STJ sobre a questão a ele submetida (SILVA, 2011).

A título de exemplificação, apresenta-se a decisão do Superior Tribunal de Justiça (STJ) que suspendeu a tramitação das mais de 50 mil ações judiciais existentes em todo o País que pedem a mudança no índice de correção monetária dos saldos das contas do Fundo de Garantia do Tempo de Serviço (FGTS).

O "trecho" escolhido como paradigma para ser julgado pelo STJ foi do Recurso Especial 1.381.683/PE:

No apelo especial, a parte recorrente alega violação dos artigos $3^{\circ}, \S 1^{\circ}$, da Lei n. 5.107/66; 11 da Lei n. 7.839/89; 13 da Lei n. 8.036/90 e 19 do Decreto n. 99.684/90, assim como divergência jurisprudencial, ao argumento de que deve ser afastada a TR como índice de correção monetária dos saldos das contas de FGTS, a fim de se preservar o valor real da moeda. Verifica-se que a discussão dos autos ainda não foi submetida por esta Corte ao rito dos recursos especiais repetitivos. Assim, tendo em vista a multiplicidade de recursos a respeito do tema em foco, admito o processamento do presente recurso repetitivo, a fim de que a controvérsia seja dirimida no âmbito da Primeira Seção do STJ e, para tanto, determino a adoção das seguintes providências: a) dê-se vista ao Ministério Público para parecer, em quinze dias (art. $3^{\circ}$, II); b) comunique-se, com cópia da presente decisão, aos Ministros da $1^{\text {a }}$ Seção do STJ e aos Presidentes dos Tribunais Regionais Federais, nos termos e para os fins previstos no art. $2^{\circ}, \S 2^{\circ}$, da Resolução n. 
$8 / 2008$; c) suspenda-se o julgamento dos demais recursos sobre a matéria versada no presente apelo nobre, consoante preceitua o $\S 2 .^{\circ}$ do art. $2 .^{\circ}$ da Resolução/STJ n. 8/2008.

O processo em apreço ainda não fora julgado, restando ao "todo" cerca de 50.000 casos de todo o país, que encontram-se sobrestados (parados) - aguardar seu julgamento para então utilizar a decisão de um caso para o provimento ou não de seu pleito.

Restou evidente que a ideia de fractais, quando aplicada nos casos de julgamento de Recursos Repetitivos de matéria cível, adéqua-se perfeitamente. Não é possível afirmar, contudo, se o fractal escolhido representará efetivamente o todo, ou que a decisão tomada a partir do paradigma selecionado seria a melhor para o caso concreto.

O certo é que este instituto, incluído no ordenamento processual brasileiro desde 2008, e preservado pelo legislador quando da edição do novo Código Processual Civil de 2015, colabora para a construção de um direito jurisprudencial moderno, substanciado no princípio da segurança jurídica e da celeridade processual, garantias constitucionais que têm sido deixadas ao acaso pelos órgãos julgadores de todo o país, seja por dificuldades de ordem material ou humana, mas que nem por isso deixaram de ser pilares essenciais ao judiciário brasileiro.

Outro aspecto da fractalidade do direito são os princípios que perpassam todos os microssistemas do direito e são evocados em todas as suas instâncias de julgamento, tornando o direito administrativo, civil e penal, semelhantes em alguns aspectos (auto-semelhança).

\section{TEORIA DO CAOS: ORDENAMENTO JURÍDICO COMO ATRATOR}

Quando um sistema aparentemente determinista - isto é, um sistema regido por leis que permitem determinar univocamente os valores das variáveis que o caracterizam, partindo dos valores dessas mesmas variáveis anteriores, resulta em trajetórias próximas que dispersam rapidamente ao passar o tempo (PRIGOGINE; STENGER, 1990) diz-se que este sistema tem comportamento caótico. 
O pressuposto tácito acerca da previsibilidade unívoca em tais sistemas não mais pode ser sustentado. Remonta da segunda metade do século XIX a percepção por parte de alguns cientistas de que tal fato poderia acontecer, por exemplo Henri Poincaré (1854-1912), ao tratar da previsibilidade:

\begin{abstract}
Se conhecêssemos perfeitamente as leis da natureza e a situação do universo no instante inicial, estaríamos aptos a predizer a situação do mesmo universo em um instante subseqüente. Mas mesmo quando as leis da natureza não são um segredo para nós, podemos conhecer a situação inicial apenas aproximadamente. Se tal nos permitisse prever a situação subseqüente com o mesmo grau de aproximação, isto seria tudo o que desejaríamos e diríamos que o fenômeno foi previsto, que ele é regido par leis. Mas não é sempre assim; pode acontecer que pequenas diferenças na situação inicial produzam grandes diferenças nos fenômenos finais; um erro antecedente pode produzir um erro enorme depois. A predição se torna impossível e temos um fenômeno fortuito (POINCARÉ, 1990, p307).
\end{abstract}

Os sistemas regidos por equações não-lineares, candidatos a apresentarem comportamento caótico, começaram a ser estudados com detalhe após a segunda metade do século XX com o advento dos grandes computadores (GLEICK, 1990).

Uma lição importante oriunda do caos determinista é que mesmo que a natureza seja completamente determinada, o futuro ainda poderá apresentarse, até para aquele que detém o conhecimento das leis naturais, cheio de possibilidades. O caos não é constituído em um argumento contra o determinismo, mas mostra que a previsibilidade, como sonhada por Laplace, nem sempre é concretizável (SILVEIRA, 1993).

Para se ter um direito mais próximo da realidade, segundo Sotomayor (2005), é necessário invocar os conceitos da Teoria do Caos ou Teoria da Catástrofe. O direito é uma ciência que requer um sistema que conjugue os opostos como parte de sua própria natureza, no qual a argumentação não está codificada desde a sua origem em normas conceituadoras. Ele exige um marco teórico mínimo, juntamente com sua revisão no momento em que é aplicado na realidade. 
Nesse sentido, legisladores e juízes devem encontrar um caminho que harmonize suas diferenças para conduzir a atividade a um modelo holístico, no qual as situações legisladas possam ser recriadas pelos juízes sem provocar a temível insegurança jurídica.

Sotomayor (2005) destaca ainda que os sistemas jurídicos lineares precisam de uma revisão para abandonar o principio de que o todo é igual em suas partes, e suas partes ao todo, já que uma mudança no comportamento dos elementos em um pequeno setor muda os resultados, o chamado "efeito borboleta"2.

Existem atualmente aspectos que, apesar de não escaparem ao direito, não conseguem efetivamente ser contemplados. O meio ambiente, por exemplo, tem sofrido com a implementação violenta do paradigma antropológico dominado pela lei do valor e do homo economicus, que resulta em um comportamento utilitarista, em contraposição a qualquer projeto humanista de socialização e evolução da arquitetura humana em harmonia com este.

Em algumas situações o direito apropria modelos de esquetes simplificadas para soluções de litígios. Contudo não se vislumbra modelos/padrões de julgamento que consigam contemplar toda a complexidade ambiental. Para preservação do bem comum e a garantia de um meio ambiente ecologicamente equilibrado às futuras gerações (art. 225, caput, $\mathrm{CF}$ ), é preciso que as instituições jurídicas sejam flexíveis, com objetivo de acolher as indeterminação das circunstâncias e dar nova interpretação aos fatores que apontam para outra concepção científica.

É necessário ainda instrumentá-los como sistemas abertos que buscam a justiça e não só a aplicação da lei, a fim de dar ao homem e ao meio ambiente um espaço para afirmar sua liberdade e conviver em harmonia.

De acordo com Sotomayor (2005, p.615), é preciso "fazer do direito um lugar comum, onde as diversas expressões abram um diálogo, evitando-se o silêncio que produz a aprovação, que conduz à ignorância, à violação do principio do conhecimento e da busca pela verdade".

2 que refere-se à dependência sensível às condições iniciais dentro da Teoria do Caos. 
No exercício de aplicação da teoria do caos ao direito ambiental é possível pensar ainda na formação de atratores, que podem ser definidos como o comportamento que um sistema dinâmico, que independentemente do ponto de partida, tem a tendência para convergir para um ponto (GLEICK, 1990).

O sistema caótico é considerado imprevisível, porém ocorre o fato estranho: ao mesmo tempo em que o sistema é caótico, paradoxalmente converge para um atrator determinado. Assim é o direito ambiental, o meio ambiente é complexo e imprevisível, contudo as decisões que o cercam convergem para problemas e soluções comuns.

Sugere-se para o direito ambiental a criação de um conjunto de atratores pautados em fatores indispensáveis ao julgamento de uma demanda ambiental, essencialmente, aquelas que envolvam o binômio "desenvolvimento" x "meio ambiente". Por exemplo: fauna e flora atingidos; aspectos sociais e culturais da comunidade deslocados pelo empreendimento; interferências no relevo, entre outros, que façam com que os julgadores não exerçam apenas a mera aplicação da legislação.

Para exemplificação da aplicação da teoria do caos às questões ambientais, foi selecionado o caso da construção da Hidrelétrica de Belo Monte no Estado do Pará, que enfrenta 15 processos na Justiça, ajuizados pelo Ministério Público Federal, sob alegação de violação de direitos indígenas, licenciamento inadequado e ausência de dados completos no Estudo de Impacto Ambiental.

Ao analisar os processos relativos aos danos oriundos da construção da referida barragem, os julgadores deverão assumir uma postura inovadora e liberta de decisões anteriores, tendo em vista a peculiaridade e a complexidade envolvidas nestes casos.

Mesmo que sejam utilizados outros julgamentos envolvendo problemas com usinas hidrelétricas, em outros estados do país, não há como se aplicar os mesmos resultados, tendo em vista a diversidade biológica e humana que cada área afetada contempla. Umas mais, outras menos, mas a verdade é que os impactos podem até parecer similares, mas na verdade, ao tomá-lo de perto, é 
possível verificar as variáveis específicas de cada caso. É por isso que se sugere a idealização de "atratores ambientais", para servir de parâmetro para o julgador, tendo em vista que todas as questões ambientais envolvendo aquela problemática específica convergem para os mesmos pontos de análise do judiciário.

No caso proposto, mesmo que o objeto de análise seja a construção de uma usina hidrelétrica (situações idênticas), as áreas geográficas atingidas são diferentes (Espírito Santo e Pará), e portanto, devem provocar resultados diferentes. É possível, contudo, a delimitação de atratores que se repetem nas duas situações e que devem ser observados no momento da produção das decisões, conforme é representado na figura 3:

Figura 3: Relação do Caos e o Direito Ambiental
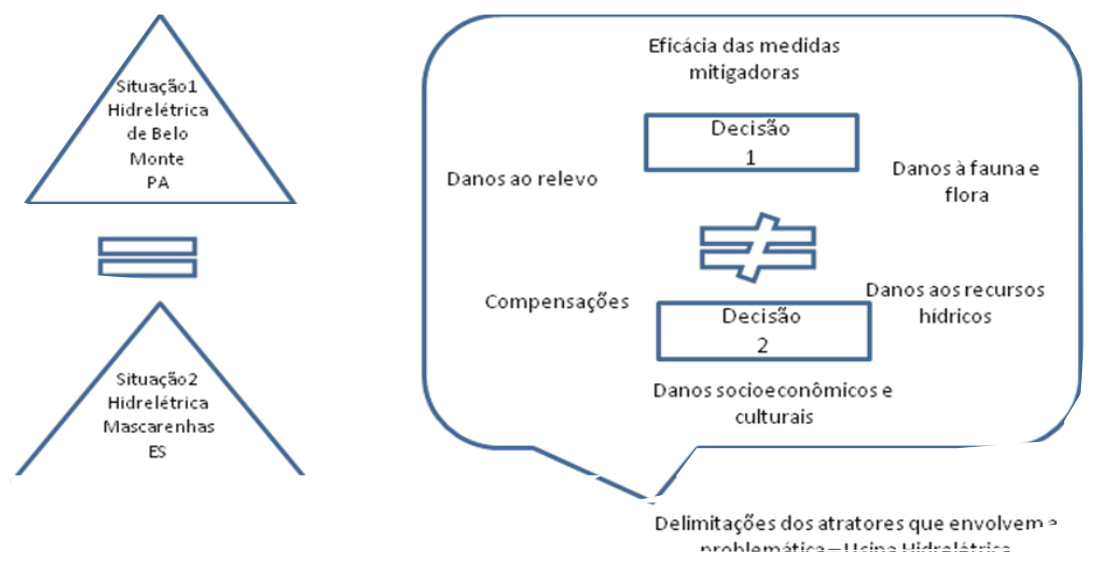

Fonte: Autores, 2020.

$\mathrm{Na}$ abordagem perspectivista aplicada ao direito, Santilli (2004) propõe inclusive um regime jurídico de proteção aos conhecimentos tradicionais associados à biodiversidade, por reconhecer que estes conhecimentos transcendem a dimensão econômica e permeiam o domínio das representações simbólicas e identitárias, que devem ser resguardadas e protegidas pelo legislador.

Santilli (2004, p.15):

destaca que a criação de um regime jurídico verdadeiramente sui generis e apropriado a proteção do conhecimento tradicionais deve basear-se nas concepções do pluralismo jurídico e no reconhecimento da diversidade jurídica existente nas sociedades tradicionais, expressão de sua diversidade cultural. 
Os antropólogos são, de um lado, fascinados pela recorrência de padrões sociais, como pudemos observar nos casos jurídicos do determinismo e da probabilidade; de outro, mostram-se céticos ou desconfortáveis quanto a elucidar esses padrões sob a forma de um sistema (LUCIANI, 2001). "Enfatizam, ao mesmo tempo, regularidade e imprevisibilidade, as similaridades da humanidade e a particularidade do sujeito humano, determinismo e caos" (LUCIANI, 2001, p. 95).

Se em alguns aspectos do direito é possível observar a regularidade e repetitividade de resultados, como nos exemplos apresentados, em outros, como nas demandas ambientais, temos apenas atratores que ditam princípios sob os quais as soluções devem ser construídas. Nada parecido com o conservadorismo legalista do STF enfrentado por Bezerra (2012).

Há outro aspecto dos sistemas dinâmicos não lineares, próprio de sistemas que levam a bifurcações e caos, que tem auxiliado os advogados hábeis a mudar uma sentença previsivelmente desfavorável, pois uma pequena alteração na condição inicial acarreta grandes mudanças.

\section{CONSIDERAÇÕES FINAIS}

Uma tipologia foi descrita a partir de diferentes aplicações das quatro teorias matemáticas a casos jurídicos concretos, mas sempre na tentativa de descrever um modelo da realidade, e seguindo uma linha de construção de um direito jurisprudencial que se mostrou possível nas quatro situações apresentadas.

1 Determinismo jurídico: Grande uniformidade doutrinária com regras precisas de aplicação. Problemas jurídicos desta espécie têm seu desfecho previsível e podem ser documentados por uma abundante jurisprudência.

O análogo matemático de tais situações são sistemas determinísticos que seguem uma equação matemática bem definida para os quais, conhecendo-se alguns parâmetros, é possível antecipar uma situação futura. Um exemplo prático é encontrado na balística. Calculando-se os parâmetros da trajetória de um míssil é possível abatê-lo em pleno ar por um antimíssil. 
2 Divergência doutrinária e plasticidade legislativa: Posições doutrinárias não sedimentadas ainda, embora com certo grau de hegemonia por alguma corrente somadas a princípios que permitem uma flexibilidade interpretativa.

Problemas jurídicos desta espécie têm um desfecho probabilístico, pois dependem da visão pessoal do julgador frente as doutrinas subjacentes. É possível conhecer a probabilidade da resposta pelo acúmulo estatístico dos resultados jurisprudenciais, contudo a exata solução da lide depende de conhecer o juiz. Dois aspectos ressaltam-se nestes casos:

a) Casos semelhantes com resultados diferentes, quando julgados por juízes diferentes.

b) As posições hegemônicas só transparecem quando julgados em Tribunais.

O análogo matemático de tais situações serviram para explicar a mecânica quântica e a desintegração radioativa. Em uma amostra de urânio radioativo é possível saber em quanto tempo metade dos átomos irão desintegrar-se (meia-vida do urânio 235.703,8 milhões de anos), porém é impossível saber exatamente quando determinado átomo se desintegrará, podendo ocorrer em frações de segundos ou várias vezes o valor da meia-vida.

3 Princípios comuns na construção do direito: Qualquer ramo do direito ou qualquer um dos seus vários microssistemas guardam princípios comuns que podem ser reconhecidos por todos, embora sejam denominados ou operados de modos distintos. Isto traz uma característica de semelhança ao direito, que the confere unidade.

É uma compreensão de que numa parte qualquer do direito encontrase todo o direito. A visão que a parte representa o todo pode ser visualizada em julgamento de demandas repetitivas.

O análogo matemático de tal situação encontra-se na definição de fractal. Sistemas do mundo físico, que devido a um processo construtivo natural ou artificial, reproduzem em diversas escalas de tamanho as suas mesmas características. 
Sistemas fractais ficam melhor descritos por dimensões fracionárias. Por exemplo, uma superfície sólida que deveria ter dimensões geométrica 2, de um plano, pode ser melhor descrita por uma dimensão geométrica entre 2 (plano) e 3 (volume) se a intensidade e o padrão de sua rugosidade assim se mostrarem úteis para tal finalidade.

4 Ordenamento jurídico como atrator: Situações únicas e complexas esbarram na carência legislativa e na inadequação da jurisprudência para o caso concreto. Não é esperado que haja respostas idênticas para casos parecidos e nem que haja respostas díspares, pois o ordenamento jurídico é o mesmo. O que é possível esperar é que as respostas sejam mais ou menos próximas por serem atraídas pelos mesmos princípios balizadores existentes no ordenamento jurídico.

O análogo matemático de tais situações é a teoria da catástrofe ou do caos, que prevê resultados diferenciados mesmo para pequenas diferenças nas condições iniciais.

Além disto, mesmo as respostas aparentemente díspares convergem para os denominados atratores. Um exemplo disto é o clima da terra cuja pequena alteração nas águas do pacífico pode levar a padrões do tipo El niño ou La niña, alterando o clima de todo o globo.

No campo jurídico, muitas das questões ambientais têm este padrão de complexidade, pois arrastam consigo questões econômicas, sociais, culturais, políticas, etc., que devem ser equalizadas e tornam o caso concreto único.

Compreender o direito a partir de modelos matemáticos é identificar, no direito, as mesmas complexidades da descrição do mundo físico e delas extrair uma tipologia sem, contudo, aplicá-las como fazem as ciências físicas.

\section{REFERÊNCIAS}

BEZERRA, Ana Keuly L. Justiça ambiental: uma análise à luz da Constituição Federal e de sua ocorrência na cidade de Teresina-PI. Teresina, 2012. 100 p. Dissertação (Mestrado em Desenvolvimento e Meio Ambiente). Universidade Federal do Piauí. 
BOYER, Carl B. História da matemática. Tradução Elza F. Gomide. 2.ed. São Paulo: Edgard Blucher, 1996.

CARAÇA, Bento de Jesus. Conceitos fundamentais de matemática. 5. ed. São Paulo: Gradiva, 2003.

CONSTITUIÇÃO FEDERAL. Constituição Federal da República Federativa do Brasil, 1988.

CÓDIGO DE PROCESSO CIVIL. Lei nº 13.105 de 16 de março de 2015. Disponível em: http://www.planalto.gov.br/ccivil_03/_ato2015-2018/2015/lei//13105.htm. Acesso em 02 ago. 2020.

GLEICK, J. Caos: a criação de uma nova ciência. Rio de Janeiro: Campus, 1990.

HEISENBERG, Werner. Física e filosofia. Trad. Jorge Leal Ferreira. Brasília: Universidade de Brasília, 1981.

LAPLACE, P.S. Probability. In: HUTCHINS, M.A., ADLER, M.J., FADIMAN, C. Gateway to the great books. - Mathematics. Chicago: Encyclopaedia Britannica, 1990.

LUCIANI, José Antonio Kelly. Fractalidade e troca de perspectivas. Mana: Estudos de Antropologia Social, v. 7, n. 2, p.95-132, 2001.

MARTINS, Daniel Felipe Neves. Determinismo, acaso, caos determinista e suas aplicações além das ciências físicas e da matemática: um olhar em direção à vida. Temas e conexões, Ano 1, n.1, p. 1-10, 2011.

MOREIRA, I.C. Os primórdios do caos determinístico. Ciência Hoje, v. 14, n.80, p.10-16, 1992.

POINCARÉ, H. Chance. In: HUTCHINS, M.A, ADLER, MJ., FADIMAN, C. Gateway to the great books. Chicago: Encyclopaedia Britannica, 1990.

POPPER, K.R. O universo aberto: Argumentos a favor do indeterminismo. Lisboa D. Quixote,1988.

PRIGOGINE, I., STENGERS, I. Entre o tempo e a eternidade. Lisboa: Gradiva, 1990.

PRIGOGINE, llya. O fim das certezas: tempo, caos e as leis da natureza. Trad. Roberto Leal Teixeira. São Paulo: Unesp, 1996.

ROONEY, Anne. A história da matemática: desde a criação das pirâmides até a exploração do infinito. São Paulo: M. Books do Brasil Editora, 2012. SANTILLI, Juliana. Conhecimentos Tradicionais Associados à Biodiversidade: elementos para a construção de um regime jurídico sui generis de proteção.In: 
PLATIAU, Ana F. B; VARELLA, Marcelo Dias (organizadores). Diversidade Biológica e Conhecimentos Tradicionais. Belo Horizonte: Editora Del Rey, 2004.

SILVA, Victor Cretella Passos. Sobrestamento na origem dos recursos repetitivos (art. 543-C do CPC). Revista Jus Navigandi, Teresina, ano 16, n. 2821, 23 mar. 2011. Disponível em: https://jus.com.br/artigos/18744. Acesso em: 02 ago. 2020.

SILVEIRA, Fernando Lang da. Determinismo, previsibilidade e caos. Cad.Cat. Ens.Fís. v. 10, n.2, p. 137-147, Ago, 1993.

SOTOMAYOR, Maria Elodia Robles. Caos y derecho. In Problemas

Contemporáneos de la Filosofía del Derecho. CÁCERES, Enrique; FLORES, Imer B.; SALDAÑA, Javier; VILLANUEVA, Enrique (Orgs.) México: Universidad Nacional Autónoma de México, 2005. Disponível em:

http://biblio.juridicas.unam.mx/libros/4/1650/33.pdf. Acesso em 02 agp. 2020.

SUPERIOR TRIBUNAL DE JUSTIÇA. Consulta processual. Disponível em: http://www.stj.jus.br/sites/STJ/default/pt_BR/Consultas/Recursos-repetitivos. Acesso em 02 ago. 2020.

TELLES JÚNIOR, Goffredo. Direito quântico: ensaio sobre o fundamento da ordem jurídica. 8.ed. São Paulo: Editora Juarez de Oliveira, 2006.

TRIBUNAL REGIONAL FEDERAL DA $1^{\text {a }}$ REGIÃO. Consulta processual. Disponível em: http://processual.trf1.gov.br/consultaProcessual/index.php? secao=Pl. Acesso em 02 ago. 2020.

\section{SUBMETIDO I SUBMITTED | 12/05/2020 APROVADO I APPROVED | 17/08/2020}

REVISÃO DE LíNGUA I LANGUAGE REVIEW I Letícia Gomes Almeida

\section{ISOBRE OS AUTORES | ABOUT THE AUTHORS}

\section{ANA KEULY LUZ BEZERRA}

Doutora em Desenvolvimento e Meio Ambiente pela Universidade Federal do Piauí. Mestre em Desenvolvimento e Meio Ambiente pela Universidade Federal do Piauí. Bacharela em Administração pela Universidade Estadual do Maranhão e em Direito pela Faculdade de Imperatriz. Docente do Instituto Federal do Piauí e Docente colaboradora do Programa de Pós-Graduação em Desenvolvimento e Meio Ambiente da Universidade Federal do Piauí. Avaliadora INEP/MEC e Líder do Grupo de pesquisa e Estudos em Educação, 
Meio Ambiente, Inclusão e Política Públicas (GEMAIPP) CNPq. E-mail: analuz@ifpi.edu.br. ORCID: https://orcid.org/0000-0002-6234-2474.

\section{JOSÉ MACHADO MOITA NETO}

Doutor em Química pela Universidade Estadual de Campinas. Mestre em Química pela Universidade Estadual de Campinas. Licenciatura Plena em Ciências - Hab. em Química pela Universidade Federal do Piauí. Bacharel em Engenharia Civil pela Universidade Federal do Piauí. Licenciatura em Filosofia pela Universidade Federal do Piauí. Bacharel em Direito pela Universidade Federal do Piauí. Professor aposantado da Universidade Federal do Piauí. Pesquisador e orientandor de teses e dissertações no programa de Pósgraduação em Desenvolvimento e Meio Ambiente como professor voluntário. E-mail: jose.machado.moita.neto@gmail.com. ORCID: https://orcid.org/00000003-3268-1907.

Os autores agradecem ao CNPq pelo Auxílio à pesquisa (Universal 01/2016, Ciências Ambientais, Processo $n^{\circ}$ 401320/2016-2) e JMMN pela Bolsa de produtividade em Pesquisa (Chamada CNPq n 09/2018, Ciências Ambientais, Processo $n^{\circ}$ 304974/2018-8). 